\title{
Surgical techniques in pediatric spine surgery
}

\author{
J. C. Le Huec · J. L. Jouve $\cdot$ M. Szpalski
}

Received: 19 April 2014/Revised: 24 April 2014/Accepted: 24 April 2014/Published online: 9 May 2014

(C) Springer-Verlag Berlin Heidelberg 2014

Pediatric orthopedics is the basis of orthopedic surgery. "ortho" from the Greek word "orthos" meaning "to make straight" and "pedis" meaning "child" are the roots of the term "orthopedic", which has gradually evolved to include treatment of the entire osteo-articular system. Pediatric surgery presents particular growth-related problems [1]. Vertebral surgery of spine deformities is a major branch of pediatric surgery and it is vital to comply with strict procedures to avoid damaging effects on patients once they have become adults [2].

Non-surgical treatments are often poorly understood or not well taught, resulting in unsuitable forms of therapy. Bracing [3] has been seen to be effective. Three-dimensional analysis using a low-dose imaging system [4] such as EOS (EOS Imaging Paris, France) provides an accurate analysis of vertebral rotations as well as predictive information as to the possible evolution of scoliosis deformities [5]. Surgical treatment of deformities in children can correct or halt any unfavorable evolution of kyphoscoliotic curvature [6] and dysplastic spondylolisthesis [6]. The high potential risk of spontaneous fusion of vertebra after surgical decompression has led to performing surgical

\section{J. C. Le Huec ( $\square)$}

Spine Unit, Bordeaux University Hospital, Bordeaux, France e-mail: j-c.lehuec@u-bordeaux2.fr

\section{J. C. Le Huec}

Ortho-Spine Department, Dir Surg Research Lab, Bordeaux University Hospital, Bordeaux, France

\section{J. L. Jouve}

Service de Chirurgie Orthopédique, Hôpital Timone Enfants, Marseille, France

\section{Szpalski}

Hopitaux Iris Sud, Brussels, Belgium procedures at a distance from the vertebral axis by spineto-rib-cage distraction in strict compliance with operating procedures [7]. It is very important to know how to use screws, hooks, and other means of laminar fixation correctly to avoid any hypercorrection and post-surgical flatback syndrome, which causes long-term sagittal balance disorders. Early surgery during growth should take into account the risk of the crankshaft phenomenon described by Dubousset [8].

This supplement summarizes the current techniques used in pediatric spinal surgery based on the experience of teams recognized as experts in the field.

Conflict of interest None.

\section{References}

1. Mehta MH (2005) Growth as a corrective force in the early treatment of progressive infantile scoliosis. J Bone Joint Surg Br 87:1237-1247

2. Labelle H, Aubin CE, Jackson R, Lenke L, Newton P, Parent S (2011) Seeing the spine in 3D: how will it change what we do? J Pediatr Orthop 31:S37-S45

3. Sanders J, D'Astous J, Fitzgerald M, Khoury J, Kishan S, Sturm P (2009) Derotational casting for progressive infantile scoliosis. J Pediatr Orthop 29:581-587

4. Dubousset J, Charpak G, Dorion I, Skalli W, Lavaste F, Deguise J, Kalifa G, Ferey S (2005) A new 2D and 3D imaging approach to musculoskeletal physiology and pathology with low-dose radiation and the standing position: the EOS system. Bull Acad Natl Med 189(2):287-297

5. Deschenes S, Charron G, Beaudoin G, Labelle H, Dubois J, Miron MC, Parent S (2010) Diagnostic imaging of spinal deformities: reducing patients radiation dose with a new slot-scanning X-ray imager. Spine (Phila Pa 1976) 35:989-994

6. Drevelle X, Lafon Y, Ebermeyer E, Courtois I, Dubousset J, Skalli W (2010) Analysis of idiopathic scoliosis progression by using numerical simulation. Spine 35(10):E407-E412 
7. Harris IE, Weinstein SL (1987) Long-term follow-up of patients with grade-III and IV spondylolisthesis. Treatment with and without posterior fusion. J Bone Joint Surg Am 69:960-969

8. Campbell RM Jr, Smith MD, Hell-Vocke AK (2004) Expansion thoracoplasty: the surgical technique of opening-wedge thoracostomy. Surgical technique. J Bone Joint Surg Am 86-A(Suppl 1):51-64

9. Dubousset J, Herring JA, Shufflebarger H (1989) The crankshaft phenomenon. J Pediatr Orthop 9(5):541-550 